\title{
Reduction of power consumption during arc welding operation
}

\author{
Liudmila Sakhno ${ }^{1, *}$, Olga Sakhno ${ }^{1}$, Vitaliy Boronin ${ }^{1}$, Elena Kochetkova ${ }^{1}$, Chen $\mathrm{Hao}^{2}$ \\ ${ }^{1}$ Peter the Great St. Petersburg Polytechnic University, Polytechnicheskaya 29, St. Petersburg, \\ 195251, Russian Federation. \\ ${ }^{2}$ China University of Mining \& Technology, Xuzhou, 221116, China
}

\begin{abstract}
The work is devoted to energy saving during arc manual welding operations. Power sources for arc manual welding are rectifiers with slow or steeply falling current-voltage characteristics. The paper considers two ways of energy saving during arc welding operations. The first way is to increase the efficiency of welding by replacing the ballast rheostat with a special electronic device that regulates the welding current instead of the ballast rheostat. The second way is to increase the efficiency of the welding equipment by replacing a traditional one-bridge rectifier with the two-bridge economical rectifier. An approximate calculation of the annual economic effect from the replacement of a ballast rheostat by the electronic regulating device is given on the example of welding operations in a typical assembly shop.
\end{abstract}

\section{Introduction}

At present, energy saving is one of the priority tasks. This is due to the shortage of basic energy resources, the growing cost of their extraction, as well as to global environmental problems [1-3].

Energy saving requires the efficient use of energy resources through the use of innovative solutions. They must be technically feasible, economically justified, acceptable from an environmental and social point of view [4-7]. The main efforts to save energy are concentrated in the sphere of electricity consumption. The main role in increasing the efficiency of energy use in the production sector belongs to modern energy-saving technologies [8-10]. At the same time, it is known that in industrial enterprises there are many devices which produce high losses during their operations. This paper is devoted to energy saving during welding operations, which use manual arc welding performed by welding rectifiers. These rectifiers are reliable, relatively cheap apparatus that provide high quality welding. They are produced by leading welding companies [11-18]. However, they have a low efficiency. The paper considers two ways of energy saving during welding operations. The first way is to replace the ballast rheostat in welding equipment with a special electronic device (chopper), regulating welding current [18], to improve the efficiency of welding operations. However, this solution increases the cost of the welding apparatus. Therefore, it is necessary to assess the economic effect of such a replacement.

\footnotetext{
${ }^{*}$ Corresponding author: Lsahno2010@yandex.ru
} 
The second way is to increase the efficiency of the rectifier due to using special electric circuit solution (double-bridge rectifier) instead of traditional solution (single-bridge rectifier).

\section{Methods}

Methods for the calculation of the currents and voltages in the new energy-saving welding apparatuses are necessary for the development and implementation of the proposed technical solutions. Calculations of the currents and voltages are produced with Matlab [19]. In addition we use Quickfield [20] for calculations of electromagnetic parameters of these apparatuses. The explanation of saving electricity due to replacing ballast rheostat with a chopper is given on the basis of simple well-known expressions for power. The evaluation of the economic efficiency of the replacement of ballast rheostats with chopper is carried out according to the standard method [21].

\section{Results and Discussion}

\subsection{Using choppers for reducing power consumption in multi-station welding system}

Manual arc welding with individual electrodes is widely used for many purposes. In repair or assembly shops a multi-station systems are often used to power the welding posts [22]. This system includes a common power source which consists of one or several rectifiers, a busbar and a post-device with ballast rheostats (Fig. 1). These systems are powered by a three-phase network.

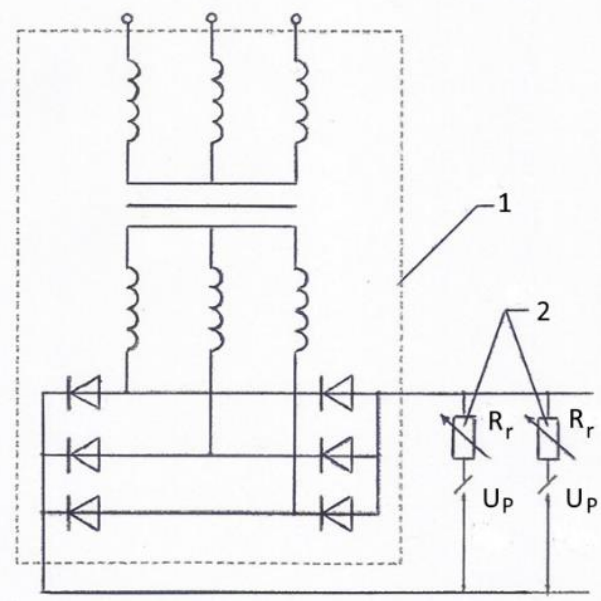

Fig.1. Schematic diagram of multi-station welding system. 1-rectifier, 2 -ballast rheostats.

The busbar is common for the entire workshop. To ensure the independence of the posts, the external characteristic of the power supply $U=f\left(I_{\text {load }}\right)$ ( $U$ is the voltage on the output of the rectifier, $I_{\text {load }}$ is the load current) must be slow falling and to ensure stable arc burning, the external characteristic of the post should be steeply falling (Fig. 2) [20]. 


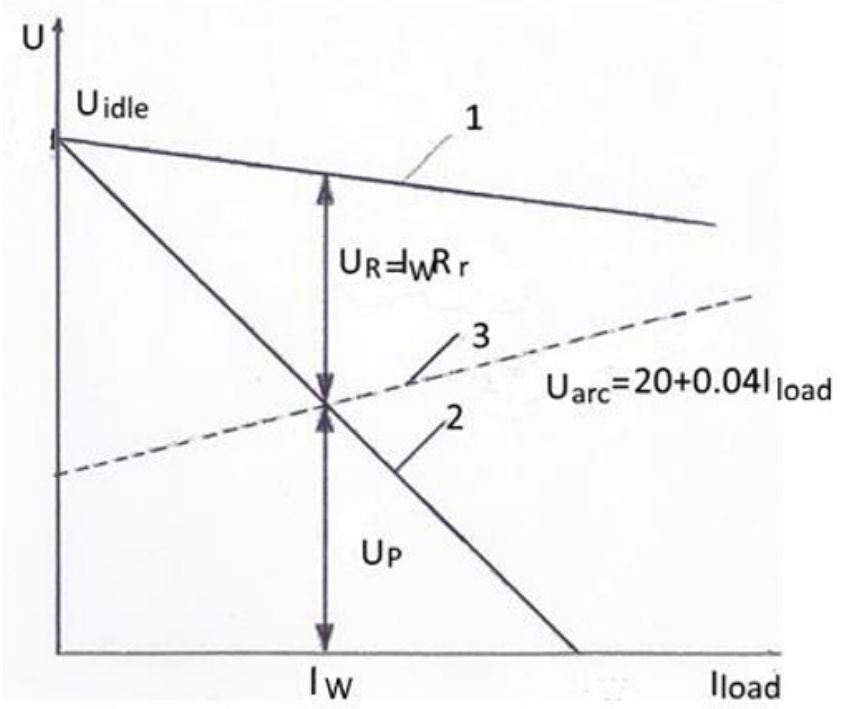

Fig.2. The external characteristics of the rectifier (1) and the post with the ballast rheostat (2), the conditional operating characteristic of the arc (3)

In order to form the necessary external characteristic, the postal devices-ballast rheostats $R_{r}$ (Fig.1) are installed at the output of the rectifier. Fig. 2 shows the conditional operating characteristic (straight 3) of the arc $U_{\text {arc }}=f\left(I_{\text {load }}\right)$, where $U_{\text {arc }}$ is the voltage on the arc [23]. The intersection of lines 2 and 3 determines the welding current $I_{W}$. It can be seen from Fig. 2 that a voltage drops on the ballast rheostat $U_{R}$, which can be up to $50 \%$ of the idling voltage of the rectifier. This drop leads to very high losses of electric power in the rheostat where the losses in the rheostat are the voltage on the rheostat multiplied the welding current. The consequence of these losses is the low efficiency of the entire multipost system, which is $48-50 \%$, and the significant costs of paying for electricity during its operation.

Simplicity, convenience in operation and cheapness of ballast rheostats are their main advantages and explain the wide use of ballast rheostats in multi-station systems, despite the fact that they are the reason for such low efficiency of the multi-station system and overestimated almost twice the cost of paying for electricity during its operation.

The high charge for electricity and its rather rapid growth pose the task of replacing ballast rheostats with more economical devices. One of them is a chopper, which is made according to the scheme of the step-down transistor converter. They provide a steeply falling external characteristic of the post and the regulation of the welding current, that is, they perform all the functions of ballast rheostats and at the same time have an efficiency of 93\%, which almost doubles the efficiency of the multi-station system.

Despite all the indicated advantages of choppers, their introduction is associated with significant capital investments, as they are approximately an order of magnitude more expensive than ballast rheostats. However, it will be shown that the existing high cost of electricity makes it economically justified to replace the rheostats with chopper. 


\subsection{Using double-bridge economical rectifiers for reducing power consumption during arc welding operations}

Let us show another way of the possibility of saving power consumption. This way is based on using double-bridge rectifiers [24]. It is known that the conventional single-phase rectifier for manual arc welding with steeply falling current-voltage characteristics consists of a transformer with increased flux leakage, a diode bridge and a smoothing choke. The smoothing choke must be used in a single-phase rectifier. The double-bridge rectifiers are very simple devices, which at a price are quite comparable with conventional rectifiers [2426]. They contain of a three-winding transformer with the primary winding 1 and two secondary windings 2 and 3 loaded with diode bridges 4 and 5 (fig. 3 ).

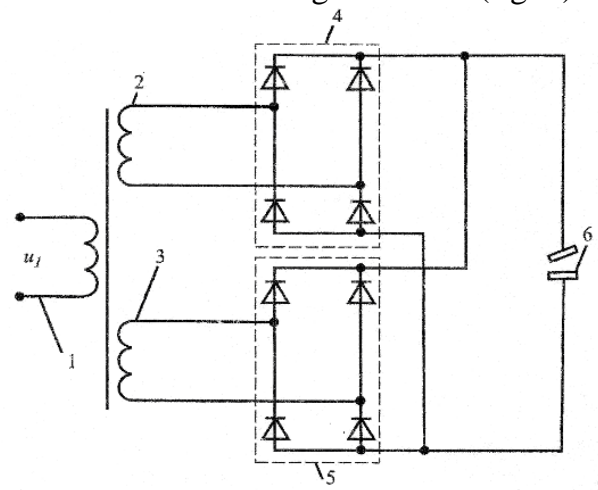

Fig. 3. Electric circuit of the double-bridge welding rectifier

The bridge outputs are connected in parallel with the arc gap 6 . Winding 2 and bridge 4 are designed to initiate and maintain stable arcing, while winding 3 and bridge 5 provide the main operating current.

The mass and power consumption of such a rectifier are less than those of a conventional rectifier, since the main part of the welding current is the current of winding 3 and there is no a smoothing choke in the double-bridge rectifier. A series of two-bridge rectifiers was developed. For example, double-bridge welding rectifier with the operating current 200 A was developed. It has $30 \%$ lower power consumption than the traditional one. This result was confirmed experimentally.

\subsection{Calculating the economic effect of expected energy savings in assembly shops by replacing ballast rheostats with chopper.}

Manual arc welding is widely used in industry. The largest number of posts is installed in the assembly shops. It depends on the number of workers that are simultaneously working in the shop. Power rectifiers VDM-6303, VKSM-1000, VDM-1001, VDM-1201, VDM1601 [18] are usually used. The welding currents are from $630 \mathrm{~A}$ to $1600 \mathrm{~A}$.

The expected energy savings are determined by the difference between the power consumed when using a ballast rheostat and the power consumed when using a chopper. The power consumed by one post with a chopper is:

$$
\begin{aligned}
& P_{\text {CHOP }}=\frac{P_{W}}{v}, \\
& P_{W}=U_{W} \times I_{W},
\end{aligned}
$$

where $P_{W}$ is power required for welding, $U_{W}$ is voltage on the arc, $I_{W}$ is welding current, $v$ is the efficiency of a chopper. 
Since the efficiency of these devices is $93 \%$, the power consumed by a post is slightly different from the power required for welding. The power $P_{R}$ consumed by one post with a ballast rheostat depends on the idling voltage of the rectifier (not voltage on the arc) because of rheostat heating :

$$
P_{R}=U_{i d l e} \times I_{W}
$$

where $U_{i d l e}$ is the idling voltage of the rectifier.

Taking into account the efficiency of the rectifier itself, we have the power consumed by one post with a chopper:

$$
P_{C H O P}^{\prime}=\frac{P_{C H O P}}{v_{r e c}},
$$

where $v_{r e c}$ is the efficiency of the rectifier.

The power consumed by one post with the ballast rheostat:

$$
P_{R}^{\prime}=\frac{P_{R}}{v_{\text {rec }}} \text {. }
$$

Thus, the saving of power consumption is mainly determined by the difference between the voltage on arc and the idle voltage of the rectifier:

$$
\Delta P=P_{R}^{\prime}-P_{C H O P}^{\prime}=\frac{I_{W}}{v_{\text {rec }}} \times\left(U_{\text {idle }}-\frac{U_{W}}{v}\right)
$$

We used these formulas in the technique of economic effect calculations [21] in a typical assembly shop, in which 12 workers are working at the same time. Let us consider that in this shop there are four multi-system rectifiers with VDM-1201 $\left(v_{\text {rec }}=0,9, U_{\text {idle }}=65\right.$ V) and the chopper $R I-322(v=93 \%)$. Each rectifier has 3 ballast rheostats. The number of rheostats in the shop is equal to the number of workers and is 12 pieces. Welding current is 300 A. Input for calculation:

- capital investments in a rectifier with a ballast rheostat 4500 rubles,

- capital investments in a chopper 47500 rubles,

- work is carried out in two shifts for 12 hours each,

- electricity tariff is $3.5 \mathrm{rub} / \mathrm{kWh}$.

The main results of the calculations are summarized in the table:

\begin{tabular}{|l|l|}
\hline Expected power savings for one post for the year, $\mathrm{kWh}$ & 37439.7 \\
\hline Payback period of the chopper RI-322, months & 11 \\
\hline Expected power savings of 4-station system, $\mathrm{kWh}$ & 449276.4 \\
\hline $\begin{array}{l}\text { The expected savings on the electricity bill for the 4-station system } \\
\text { for the year in rubles }\end{array}$ & 790276.8 \\
\hline Annual economic effect for the 4-station system in rubles & 712876.8 \\
\hline
\end{tabular}

\section{Conclusions}

The efficiency of the multi-station system for manual arc welding with ballast rheostats can be significantly increased by replacing rheostats with choppers. It reduces the cost of consumed electricity. The annual economic effect in the shop with 12 rectifiers can be more than 700 thousand rub. 
Replacing the traditional rectifier with steeply falling current-voltage characteristics by a two-bridge economical rectifier results in a reduction in power consumption by approximately $30 \%$.

\section{References}

1. T.D. Gerarden, R. G. Newell, R. N. Stavins, J. of Economic Literature, 55 (4), 14861525 (2017)

2. A. L. Facci, V.Cigolotti, E. Jannelli, S. Ubertini, Applied energy, 192, (2017)

3. M. Filippini, L. C. Hunt. Energy Economics, 52, S5-S16 (2015).

4. A. Zerrahn, W. P. Schill, C. Kemfert, arXiv preprint arXiv:1802.07885 (2018)

5. C. Bojnec, D. Papler, J. of Business Economics and Management, 12(2), (2011)

6. S. Sorrell. Sustainability J., 2(6), (2010)

7. G. E. Halkos, N. G. Tzeremes, J. of Renewable and Sustainable Energy, 5(4), (2013)

8. G. Turichin, M. Kuznetsov M, Sokolov, A. Salminen. Physics Procedia, 78, (2015)

9. V. Karkhin, M. Rethmeier, J. Welding in the World, 59(4), (2015)

10. A. Kazakov, E. Kazakova, M. Karasev, D. Lubochko, J. Material Performance and Characterization, 6(3), (2017)

11. Miyachi Europe [web site]:-Access mode: http://www.miyachieurope.com; http://www.ostec-micro.ru

12. CEA [web site ]:-Access mode: http://www.ceaweld.com/en/index.htm

13. Bosch Rexroth [web site]:-Access mode: http://www.boschrexroth.com/business_units/brc/subwebsites/catalog/widerstandsschw eissen/en/index.jsp?

14.Ideal Werk [web site]:-Access mode: http://www.ideal-werk.com/unternehmen/idealwelding-systems.html

15. Soudax [web site]:-Access mode: http://weber.ru/search.php\#maker=42 ; http://www.soudax.fr/index.php?page=fiche_produit\&from=recherche\&pid=129\&row_ num $=8 \&$ rubid $=5$

16. Chowel [web site ]:-Access mode: http://americanchowel.com/Products/5-2.htm

17. Nimak [web site]:-Access mode: http://www.shtorm-its.ru/kat/nimak.pdf . -

18. Electric-Mics [web site]: Access mode: http://www.elmics

19. http://mathworks.com

20.J.R. Claycomb, Applied Electromagnetics Using QuickField and MATLAB. Laxmi Publications, Ltd., (2010).

21. V.F.Palij, L.P.Suzdal'cev. Tekhniko-ekonomicheskij analiz proizvodstvennohozyajstvennoj deyatel'nosti mashinostroitel'nyh predpriyatij: Mashinostroenie, 272p (1989).

22. K. Weman, Welding processes handbook, New York: CRC Press, ISBN 0-8493-1773-8 (2003)

23. GOST 2889-91.

24. L.I. Sakhno, J. Electrical Technology Russia, 1, ( 2002)

25. L.I. Sakhno. J. Welding International, 17(7), (2003)

26. L. Sakhno, O. Sakhno, S. Dubitsky, J. Archives of electrical engineering, 64(252), (2015) 